OPEN ACCESS

Edited by:

Mikhail V. Kurushkin,

ITMO University, Russia

Reviewed by:

Sergey Makarov,

ITMO University, Russia

Vitaliy E. Gasumyants,

Peter the Great St. Petersburg

Polytechnic University, Russia

${ }^{*}$ Correspondence:

Alexey B. Tarasov

alexey.bor.tarasov@yandex.ru

Specialty section:

This article was submitted to

Inorganic Chemistry,

a section of the journal

Frontiers in Chemistry

Received: 23 March 2020

Accepted: 21 April 2020

Published: 13 May 2020

Citation:

Petrov AA and Tarasov AB (2020) Methylammonium Polyiodides in Perovskite Photovoltaics: From

Fundamentals to Applications.

Front. Chem. 8:418.

doi: $10.3389 /$ fchem.2020.00418

\section{Methylammonium Polyiodides in Perovskite Photovoltaics: From Fundamentals to Applications}

\author{
Andrey A. Petrov ${ }^{1}$ and Alexey B. Tarasov ${ }^{1,2 *}$ \\ 'Laboratory of New Materials for Solar Energetics, Department of Materials Science, Lomonosov Moscow State University, \\ Moscow, Russia, ${ }^{2}$ Department of Chemistry, Lomonosov Moscow State University, Moscow, Russia
}

Discovered in 2017, methylammonium polyiodides were proposed as a facile precursor for synthesis of hybrid perovskites by means of their interaction with metallic lead, which initiated further active exploration of their potential applications. Investigation of their unusual properties such as liquid state, unprecedented phase diversity and high reactivity revealed that methylammonium polyiodides are the first representatives of a new class of compounds - reactive polyhalide melts (RPM). In this review, we summarize the reported data on the unique properties of these compounds, discuss their potential for fabrication of hybrid perovskite films and describe the role of polyhalides in degradation of perovskite solar cells.

\footnotetext{
Keywords: methylammonium polyiodides, reactive polyiodide melts, RPM, hybrid perovskites, lead halide perovskites, perovskite solar cells
}

\section{INTRODUCTION}

Hybrid organic-inorganic perovskites with a general formula $\mathrm{APbX}\left[\mathrm{A}=\mathrm{CH}_{3} \mathrm{NH}_{3}^{+}\left(\mathrm{MA}^{+}\right)\right.$, $\left.\mathrm{CH}\left(\mathrm{NH}_{2}\right)_{2}^{+}\left(\mathrm{FA}^{+}\right) ; \mathrm{X}=\mathrm{I}^{-}, \mathrm{Br}^{-}\right]$represent a new perspective class of materials used for optoelectronic devices (LEDs, lasers, sensors, etc.) and solar cells of new generation, so called perovskite solar cells. For the last decade, unprecedented interest to these materials has arouse because of the unique combination of their properties such as strong light absorption (Lin et al., 2015), large electron and hole diffusion lengths (Dong et al., 2015), wide tunability of their properties through the selection of the composition and facile fabrication using solution-processing methods (Gao et al., 2014; Zhao and Zhu, 2016). The efforts applied to the development of perovskite solar cells lead to an outstanding growth of their efficiency from 4\% in 2009 to $25.2 \%$ in 2019 (NREL, 2020) thus overcoming record efficiencies for silicon solar cells.

Almost all proposed methods for fabrication of perovskite films rely on one of two processes: crystallization of hybrid perovskites from polar aprotic solvents (Saliba et al., 2016; Kim et al., 2019) or addition reaction between lead salt and organic salt (e.g., $\mathrm{PbI}_{2}$ and MAI) (Yang et al., 2017). While deposition from solutions remains the most common method for obtaining high-quality perovskite films due to its simplicity, the crystallization of perovskites goes through formation of solvate intermediate phases such as $(\mathrm{MA})_{2}(\mathrm{~S})_{2} \mathrm{~Pb}_{3} \mathrm{I}_{8}(\mathrm{~S}=\mathrm{DMSO}, \mathrm{DMF}, \mathrm{GBL})$ which tend to grow in a form of needle-like crystals resulting in inhomogeneous morphology and pinholes of perovskite films (Cao et al., 2016; Petrov et al., 2017b,c; Fateev et al., 2018). The process is further exacerbated with the shrinkage of film volume upon decomposition of the intermediate phases into perovskite leading to the formation of cracks. The approaches based on reaction between lead and organic salts can be implemented in two ways: either by (co-)evaporation in vacuum or using successive solution deposition. The former needs a complex vacuum equipment whereas the latter suffers 
from the incomplete reaction (Hsieh et al., 2017). The abovementioned issues provoked search and development of alternative synthesis methods.

The recent discovery of a new group of low-melting methylammonium and formamidinium polyiodides (Petrov et al., 2017a) opened a new branch of strategies for hybrid perovskite synthesis through a redox reaction with metallic lead. Because of their liquid state and high reactivity toward metallic lead, the name of such polyiodides were coined as reactive polyiodide melts (RPM). In present review, we give a generalized vision on methylammonium polyiodides and related compounds known so far in terms of their fundamental features and technological applications.

\section{LIQUID STATE}

RPM can be easily obtained by simple mixing of crystalline methylammonium iodide (MAI)/formamidinium iodide (FAI) and iodine $\left(\mathrm{I}_{2}\right)$ (Petrov et al., 2017a). If the two solid compounds are brought into contact, a liquid RPM immediately forms even at room temperature (Figure 1a). Similarly, a crystal of organic salts transforms into RPM droplet in the atmosphere containing $I_{2}$ vapors (Turkevych et al., 2019).

According to Raman spectroscopy, methylammonium polyiodides have three characteristic vibrations near $110 \mathrm{~cm}^{-1}$, $145 \mathrm{~cm}^{-1}$ and $170 \mathrm{~cm}^{-1}$ that correspond to an $\mathrm{I}_{3}^{-}$symmetrical stretch vibrations, $\mathrm{I}_{3}^{-}$asymmetrical stretch vibrations and vibrations of solvating $\mathrm{I}_{2}$ molecular units, respectively (Petrov et al., 2017a; Turkevych et al., 2019; Udalova et al., 2020).

Liquid state of the RPM is a distinctive feature, making it a special precursor for hybrid perovskites because it does not require any organic solvents and therefore exempts the fabrication process from concomitant problems. In fact, a liquid state of RPM at room temperature is not unique itself if considering the whole class of plolyiodides. However, it was previously thought that only polyiodides with large organic cations such as aromatic (e.g., imidazolium) (Thorsmølle et al., 2012; Fei et al., 2015), trialkylsulfonium [e.g., (Et $)_{3} \mathrm{~S}^{+}$] (Bengtsson et al., 1991), or tetraalkylammonium [e.g., (Oc) ${ }_{4} \mathrm{~N}^{+}$] (Stegemann et al., 1992; Wang et al., 2014; Yushina et al., 2014) are able to generate liquid phases of such polyiodides at room temperature (Bengtsson et al., 1991; Stegemann et al., 1992; Thorsmølle et al., 2012). Conversely, $\mathrm{CsI}_{3}$ has a melting point over $130^{\circ} \mathrm{C}$ (Topol, 1968).

The melting points of methylammonium and formamidinium polyiodides were found to be unexpectedly low. Detailed physicochemical analysis of the RPM revealed a complex phase diagram of the MAI- $\mathrm{I}_{2}$ system with 3 eutectics and 4 polyiodide phases $\mathrm{MAI}_{2}, \mathrm{MAI}_{2.67}, \mathrm{MAI}_{4}, \mathrm{MAI}_{5.5}$ (Figure 1b). While $\mathrm{MAI}_{2}$ and $\mathrm{MAI}_{2.67}$ phases were found to undergo peritectic and peritectoid decompositions at $23^{\circ} \mathrm{C}$ and $14^{\circ} \mathrm{C}$, the melting temperatures of $\mathrm{MAI}_{4}$ and $\mathrm{MAI}_{5.5}$ phases were determined at $35^{\circ} \mathrm{C}$ (Petrov et al., 2019).

To estimate thermodynamic stability of the crystalline polyiodides, DFT calculations were performed. The selected approach to calculate formation enthalpy and entropy values of the compounds from isolated particles $\left(\mathrm{I}^{-}, \mathrm{MA}^{+}, \mathrm{I}_{2}\right)$ demonstrated excellent agreement with experimental data for MAI and $\mathrm{I}_{2}$ and was therefore used to calculate thermodynamic state-functions of the polyiodides. The performed DFT calculations revealed that $\mathrm{MAI}_{2}$ forms due to major enthalpy contribution whereas in the case of higher methylammonium polyiodides entropy plays a crucial role in their formation (Petrov et al., 2019).

The low melting points of methylammonium polyiodides were explained by high energy of cation solvation and increase in conformational entropy upon melting. The former arises from high dipole moment of methylammonium cation along with its ability to form numerous $\mathrm{H}$-bonds therefore ensuring strong interaction with anions in a liquid state. The latter follows from the low energy barriers to rotation of the cations and their amphiphility leading to the realization of all possible cationanion conformations in the melt (Petrov et al., 2019).

According to the phase diagram, there are two compositional regions with a liquid homogeneous state of $\mathrm{MAI}_{\mathrm{x}}$ at room temperature $(3.0<\mathrm{x}<3.3 ; 4.3<\mathrm{x}<4.4)$, whereas at $40^{\circ} \mathrm{C}$ a liquid state of $\mathrm{MAI}_{\mathrm{X}}$ is observed in the wide range of compositions $(2.9<\mathrm{x}<9.0)$, which opens up great opportunities for technological application of RPM.

\section{HIGH REACTIVITY}

The RPM demonstrate high reactivity toward various metals. In particular, the reaction of RPM with metallic lead manifests an amazingly simple redox process of perovskite synthesis:

$\mathrm{MAI}_{3 \text { (liquid) }}+\mathrm{Pb}$ (solid) $->\mathrm{MAPbI}_{3}$ (solid)

The process can be implemented by spin-coating or spraying of RPM onto $\mathrm{Pb}$ films. If such treatment is followed by rinsing of the specimen with isopropanol to eliminate the unreacted RPM, large cuboid morphology of the film can be observed (Figure 1c). In case of the incomplete conversion there is $\mathrm{PbI}_{2}$ layer between the layer of unreacted $\mathrm{Pb}$ and grown perovskite layer according to XRD and SEM data. On the other hand, long contact of RPM with perovskite film leads to its recrystallization and dissolution. For instance, it was shown, that $50 \mathrm{~nm}$ thickness film of lead treated with RPM completely disappear within $15 \mathrm{~s}$ indicating that some amount of lead can be dissolved in RPM. Later experiment showed that the solubility of $\mathrm{Pb}$ is rather small and does not exceed $1 \mathrm{~mol} \%$ at room temperature and slightly increases at elevated temperatures.

The conversion of $\mathrm{Pb}$ into $\mathrm{MAPbI}_{3}$ is accompanied by volume increase in 8.4 times thus ensuring the formation of pinhole free perovskite films. This feature was successfully utilized for perovskite growth in confined space. Thin patterned perovskite films were obtained by pressing the die with a given relief containing RPM deposited onto it against the metallic lead film (Figure 1d). Because the sum of molar volumes of $\mathrm{Pb}$ and RPM is almost equal to that for $\mathrm{MAPbI}_{3}$, the proposed method allows to dose the exact amount of RPM and fabricate perovskite films with any particular relief (Grishko et al., 2019), which can improve the efficiency of the devices due to optimization of light-scattering (Wang et al., 2012). The other way to dose RPM can be the use of 


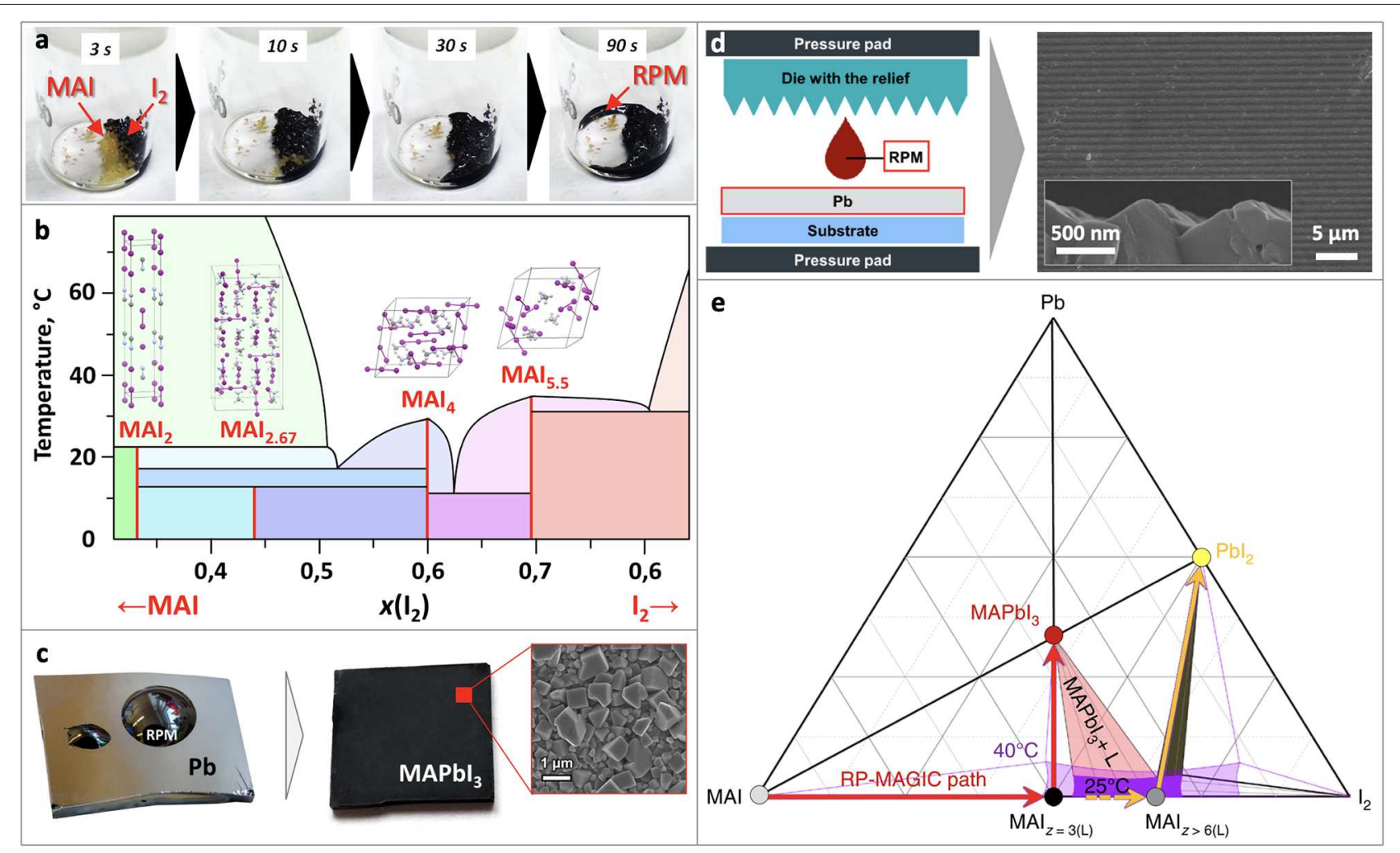

FIGURE 1 | (a) Formation of RPM from MAI and $\mathrm{I}_{2}$, (b) Phase diagram of MAI- $\mathrm{I}_{2}$, (c) perovskite film obtained by spin-coating of RPM onto Pb film, (d) scheme of a method for fabrication textured perovskite films, (e) Ternary Pb-MAl- $I_{2}$ diagram. Adapted from Petrov et al. (2017a) with permission from the Royal Society of Chemistry. Adapted with permission from Petrov et al. (2019). Copyright (2019) American Chemical Society. Adapted from Grishko et al. (2019) with permission from the Royal Society of Chemistry. Material from: "Ivan Turkevych et al. Strategic advantages of reactive polyiodide melts for scalable perovskite photovoltaics. Nature Nanotechnology, published 2018, Springer Nature".

starch to eliminate its excess through formation of RPM-starch complex (Shlenskaya et al., 2018b).

Other metals such as $\mathrm{Cu}$ and $\mathrm{Au}$ are also subject to the reaction with $\mathrm{RPM}$ resulting in formation of $\mathrm{MACu}_{2} \mathrm{I}_{3}$ and $(\mathrm{MA})_{2} \mathrm{Au}_{2} \mathrm{I}_{6}$, respectively (Petrov et al., 2018; Shlenskaya et al., 2018a). Likewise, RPM easily oxidize spiro-MeOTAD which is the most popular material for hole-transporting layer in perovskite solar cells (Shlenskaya et al., 2018a). The formation of these products is particularly important when one considers stability of perovskite solar cells and formation of RPM under operational conditions in the perovskite-based devices, which is discussed in the last section.

\section{PHASE RELATIONS IN THE PB-MAI-I 2 TERNARY SYSTEM}

Phase diagram of the $\mathrm{Pb}-\mathrm{MAI}-\mathrm{I}_{2}$ system (Figure 1e) shows the technologically relevant area, where RPM coexist with $\mathrm{MAPbI}_{3}$ (light-red triangle), which enlarges with the temperature increase. On the right side of it there is an unfavorable area in which iodine-rich RPM coexist with $\mathrm{PbI}_{2}$. A reaction between $\mathrm{Pb}$ and RPM corresponds to a linear pathway on the phase diagram from the point corresponding to a particular composition of
$\mathrm{RPM}$ toward $\mathrm{Pb}$ apex. In order to obtain pure perovskite phase, one should develop a synthetic process which does not go beyond the light-red area. Therefore, RPM should have the composition MAI $\mathrm{X}$, where $\mathrm{x}<5.5$ to avoid $\mathrm{PbI}_{2}$ formation and $\mathrm{x}>3$ (for the case of $\mathrm{T}=40^{\circ} \mathrm{C}$ ) to be liquid for ensuring effective lead conversion (Petrov et al., 2017a; Turkevych et al., 2019).

\section{PEROVSKITE SOLAR CELLS}

Although it is tricky to dose RPM precisely onto metallic lead due to its extremely high reactivity, two approaches were proposed to solve this task. The first is based on addition of a reagent which initiates RPM formation and further reaction, whereas the second is based on withdrawal of a compound which inhibits the reaction.

The first approach is named RP-MAGIC (Reactive Polyiodide Melt-Assisted Growth through in-situ Conversion), in which a stoichiometric $\mathrm{Pb} / \mathrm{MAI}$ bilayer on a substrate obtained by subsequent thermal evaporation of $\mathrm{Pb}$ and MAI is treated with iodine vapors at $40^{\circ} \mathrm{C}$ (Figure 2a). Upon the reaction of $\mathrm{MAI}_{\text {(solid) }}$ and $\mathrm{I}_{2 \text { (gas) }}$ the RPM is formed and instantly reacts with a $\mathrm{Pb}$ underlayer:

$$
\mathrm{Pb} \text { (solid) }+\mathrm{MAI}(\text { solid })+\mathrm{I}_{2 \text { (gas) }}->\mathrm{MAPbI}_{3} \text { (solid) }
$$



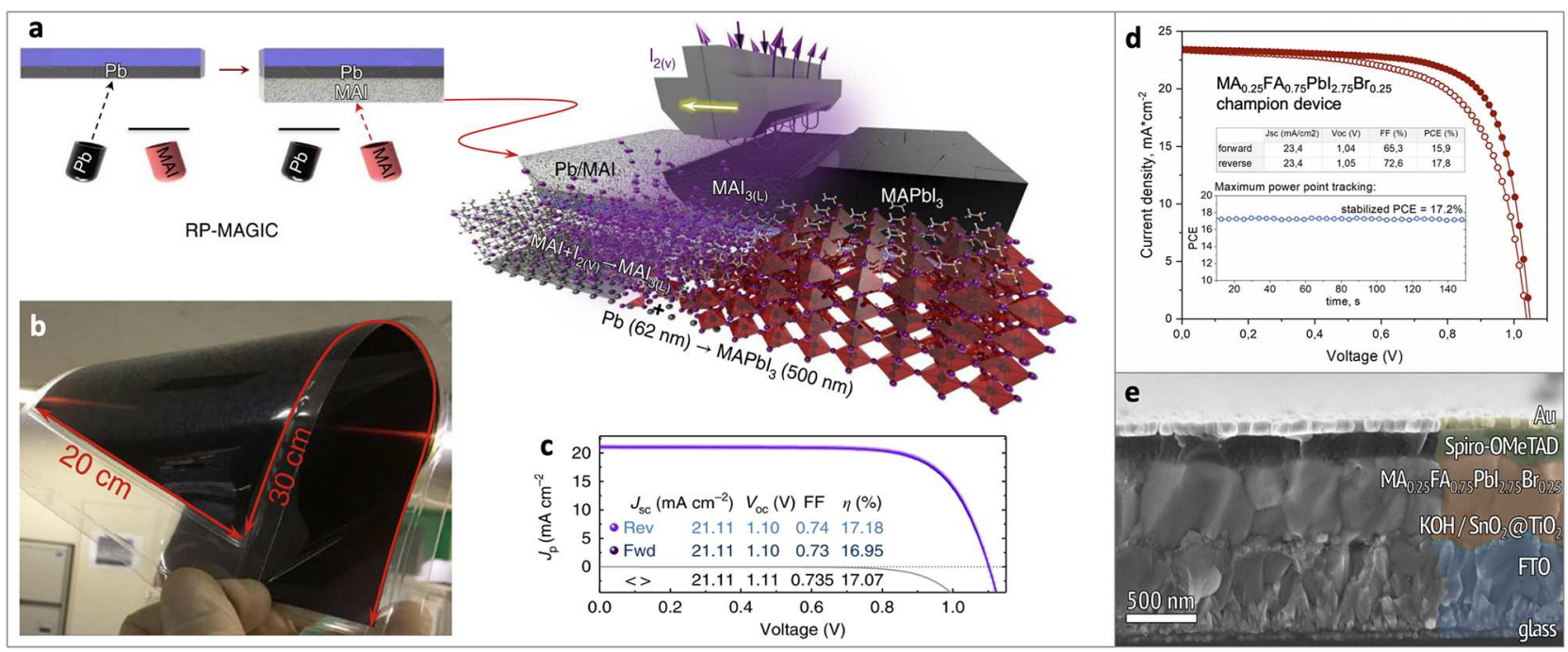

FIGURE 2 | (a) Scheme of the RP-MAGIC approach, (b) MAPbl 3 film on a $20 \times 30 \mathrm{~cm}^{2}$ flexible PET/ITO substrate obtained by RP-MAGIC approach, (c) PCE of the device obtained by RP-MAGIC approach, (d,e) PCE and cross-section of the device obtained by spin-coating of RPM solution onto Pb film. Material from: "Ivan Turkevych et al. Strategic advantages of reactive polyiodide melts for scalable perovskite photovoltaics. Nature Nanotechnology, published 2018, Springer Nature". Adapted with permission from Belich et al. (2020). Copyright (2020) American Chemical Society.

Authors demonstrated highly uniform perovskite films on relatively large area such as $100 \mathrm{~cm}^{2}$ on glass/FTO and 600 $\mathrm{cm}^{2}$ on flexible PET/ITO substrates therefore showing high scalability potential of the method (Figure $2 \mathbf{b}$ ). The solar cells fabricated using RP-MAGIC approach demonstrated power conversion efficiencies (PCE) up to $17.2 \%$ (reverse scan) in the standard $\mathrm{FTO} / \mathrm{m}-\mathrm{TiO}_{2} /$ Perovskite/Spiro-OMeTAD/Au architecture (Figure 2c) (Turkevych et al., 2019).

Another approach is a spin-coating onto $\mathrm{Pb}$ film a certain amount of RPM dissolved in isopropanol. The reactivity of RPM in such solution was shown to be inhibited by the presence of solvent molecules. Upon evaporation of isopropanol, pure RPM is formed starting to react with the lead film. Using this method high-quality perovskite films were obtained and perovskite solar cells with PCE $=17.8 \%$ (reverse scan) were demonstrated (Figures 2d,e) (Belich et al., 2020).

Although the obtained efficiency of solar cells obtained using RPM is less than that achieved by conventional solution based spin-coating approach with record values up to $21 \%$ for $\mathrm{MAPbI}_{3}$ (Chiang and Wu, 2018; Liu et al., 2019b), the first proofof-concept results obtained without advanced optimization of charge transporting layers are fair enough and comparable with other alternative approaches such as crystallization from methylamine/acetonitrile mixture (19.0\%) (Noel et al., 2017) methylamine based technology (19.3\%) (Chen et al., 2017).

To achieve the efficiencies over $22 \%$, mixed-cation and mixed-halide perovskites should be used (Yang et al., 2017; Jiang et al., 2019; Jung et al., 2019; Kim et al., 2019; Liu et al., 2019a). Such technologically attractive perovskites with mixed compositions were also successfully obtained using the proposed methods as the corresponding polyiodides have melting points below $65^{\circ} \mathrm{C}$ (Petrov et al., 2019; Turkevych et al., 2019). In particular, $\mathrm{Cs}_{0.05} \mathrm{MA}_{0.2} \mathrm{FA}_{0.75} \mathrm{PbI}_{3}$ perovskite films and corresponding devices were obtained by RP-MAGIC approach $\left[\mathrm{T}_{\mathrm{m}}\left(\mathrm{Cs}_{0.05} \mathrm{MA}_{0.2} \mathrm{FA}_{0.75} \mathrm{I}_{3}\right)=38^{\circ} \mathrm{C}\right.$ ] (Turkevych et al., 2019). Mixed compositions $\left[\mathrm{MA}_{0.5} \mathrm{FA}_{0.5} \mathrm{PbI}_{3}, \mathrm{MA}_{0.25} \mathrm{FA}_{0.75} \mathrm{PbI}_{3}\right.$, $\left.\mathrm{MA}_{0.25} \mathrm{FA}_{0.75} \mathrm{PbI}_{2.75} \mathrm{Br}_{0.25}, \quad\left(\mathrm{FAPbI}_{3}\right)_{0.83}\left(\mathrm{MAPbBr}_{3}\right)_{0.17}\right]$ were obtained by spin-coating of the RPM solutions onto $\mathrm{Pb}$ films ( $\mathrm{T}_{\mathrm{m}}$ of all corresponding polyhalides $<5^{\circ} \mathrm{C}$ ) (Petrov et al., 2019; Belich et al., 2020). Further optimization of polyhalide compositions as well as their application techniques is therefore a vital scientific task which can further improve the efficiency of the devices obtained using RPM.

\section{FORMATION OF RPM UNDER ILLUMINATION}

It is known that intensive irradiation of hybrid perovskites leads to the release of degradation products $\mathrm{I}_{2}, \mathrm{Br}_{2}, \mathrm{MAI}$, and MABr (Abdelmageed et al., 2016; Pistor et al., 2016; Wang et al., 2016; Ceratti et al., 2018). It was shown recently, that the accumulation of these compounds leads to the formation of RPM in perovskite films (Shlenskaya et al., 2018a; Udalova et al., 2020). Particularly, the fast formation of RPM under laser beam was confirmed for the six most relevant perovskite compositions: $\mathrm{MAPbI}_{3}, \mathrm{MA}_{0.15} \mathrm{FA}_{0.85} \mathrm{PbI}_{3}$, $\mathrm{FAPbI}_{3}, \quad \mathrm{FA}_{0.85} \mathrm{Cs}_{0.15} \mathrm{PbI}_{3}, \quad \mathrm{MA}_{0.25} \mathrm{FA}_{0.75} \mathrm{PbI}_{2.25} \mathrm{Br}_{0.75}$, and $\mathrm{Cs}_{0.05} \mathrm{MA}_{0.15} \mathrm{FA}_{0.8} \mathrm{PbI}_{2.5} \mathrm{Br}_{0.5}$ (Udalova et al., 2020).

Slow formation of RPM was observed under intense UV irradiation of a perovskite solar cell causing the degradation of the gold electrode through formation of $\left[\mathrm{AuI}_{2}\right]^{-}$and $\left[\mathrm{AuI}_{4}\right]^{-}$ complexes and subsequent precipitation of the $(\mathrm{MA})_{2} \mathrm{Au}_{2} \mathrm{I}_{6}$ phase on the Au/perovskite interface (Shlenskaya et al., 2018a). Ironically, methylammonium polybromides were also found to be responsible for perovskite self-healing under illumination 
(Ceratti et al., 2018) indicating a critical role of polyhalides in the photochemistry of hybrid perovskites.

\section{CONCLUSION AND OUTLOOK}

To sum up, RPM are a new class of highly reactive polyhalide compounds with a general formula $\mathrm{RHal}_{\mathrm{x}}(\mathrm{R}$ $=\mathrm{MA}, \mathrm{FA}, \mathrm{Cs} ; \mathrm{Hal}=\mathrm{I}, \mathrm{Br})$ attracting great interest in the view of their unusual physicochemical properties and potential applications. Demonstrating low melting temperatures and unprecedented phase diversity, these compounds can serve as facile precursors for perovskite solar cells fabrication and be responsible for their degradation and self-healing.

We believe that the RPM can promote the development of solvent-free methods of obtaining hybrid perovskites which is free from potential sources of contamination as the reaction between RPM and $\mathrm{Pb}$ proceeds without formation of any byproducts. Hybrid perovskites obtained using RPM demonstrate excellent optoelectronic properties and have a large range of potential applications including solar cells, photodetectors, lightemitting diodes and photonic devices.

\section{REFERENCES}

Abdelmageed, G., Jewell, L., Hellier, K., Seymour, L., Luo, B., Bridges, F., et al. (2016). Mechanisms for light induced degradation in MAPbI3 perovskite thin films and solar cells. Appl. Phys. Lett. 109:233905. doi: 10.1063/1.4967840

Belich, N. A., Petrov, A. A., Rudnev, P. O., Stepanov, N. M., Turkevych, I., Goodilin, E. A., et al. (2020). From metallic lead films to perovskite solar cells through lead conversion with polyhalides solutions. ACS Appl. Mater. Interfaces. 12, 20456-20461. doi: 10.1021/acsami.0c02492. [Epub ahead of print].

Bengtsson, L. A., Stegemann, H., Holmberg, B., and Füllbier, H. (1991). The structure of room temperature molten polyiodides. Mol. Phys. 73, 283-296. doi: $10.1080 / 00268979100101201$

Cao, J., Jing, X., Yan, J., Hu, C., Chen, R., Yin, J., et al. (2016). Identifying the molecular structures of intermediates for optimizing the fabrication of high-quality perovskite films. J. Am. Chem. Soc. 138, 9919-9926. doi: 10.1021/jacs.6b04924

Ceratti, D. R., Rakita, Y., Cremonesi, L., Tenne, R., Kalchenko, V., Elbaum, M., et al. (2018). Self-healing inside APbBr3 halide perovskite crystals. Adv. Mater. 30, 1-7. doi: 10.1002/adma.201706273

Chen, H., Ye, F., Tang, W., He, J., Yin, M., Wang, Y., et al. (2017). A solventand vacuum-free route to large-area perovskite films for efficient solar modules. Nature 550, 92-95. doi: 10.1038/nature23877

Chiang, C.-H., and Wu, C.-G. (2018). A method for the preparation of highly oriented MAPbI 3 crystallites for high-efficiency perovskite solar cells to achieve an $86 \%$ fill factor. ACS Nano 12, 10355-10364. doi: 10.1021/acsnano.8b05731

Dong, Q., Fang, Y., Shao, Y., Mulligan, P., Qiu, J., Cao, L., et al. (2015). Electronhole diffusion lengths $>175$ um in solution-grown $\mathrm{CH} 3 \mathrm{NH} 3 \mathrm{PbI} 3$ single crystals. Science 347, 967-970. doi: 10.1126/science.aaa5760

Fateev, S. A., Petrov, A. A., Khrustalev, V. N., Dorovatovskii, P. V., Zubavichus, Y. V., Goodilin, E. A., et al. (2018). Solution processing of methylammonium lead iodide perovskite from $\gamma$-butyrolactone: crystallization mediated by solvation equilibrium. Chem. Mater. 30, 5237-5244. doi: 10.1021/acs.chemmater.8b01906

Fei, Z., Bobbink, F. D., Păunescu, E., Scopelliti, R., and Dyson, P. J. (2015). Influence of elemental iodine on imidazolium-based ionic liquids: solution and solid-state effects. Inorg. Chem. 54, 10504-10512. doi: 10.1021/acs.inorgchem.5b02021
Today, further detailed physicochemical investigation of the RPM is needed to reveal the influence of various polyhalides on the functional properties of the perovskite and other accompanying materials in the devices. The objects of particular interest are RPM with mixed compositions and RPM with other cations including those which are able to form $2 \mathrm{D}$ perovskites and compounds with perovskite-like structure.

\section{AUTHOR CONTRIBUTIONS}

All authors listed have made a substantial, direct and intellectual contribution to the work, and approved it for publication.

\section{FUNDING}

This research was financially supported by the Russian Science Foundation (Project No. 18-73-10224).

\section{ACKNOWLEDGMENTS}

Authors are grateful to the team of the Laboratory of New Materials for Solar Energetics.

Gao, P., Grätzel, M., and Nazeeruddin, M. K. (2014). Organohalide lead perovskites for photovoltaic applications. Energy Environ. Sci. 7, 2448-2463. doi: 10.1039/C4EE00942H

Grishko, A. Y., Petrov, A. A., Goodilin, E. A., and Tarasov, A. B. (2019). Patterned films of a hybrid lead halide perovskite grown using space-confined conversion of metallic lead by reactive polyiodide melts. RSC Adv. 9, 37079-37081. doi: 10.1039/C9RA07613A

Hsieh, T. Y., Huang, C. K., Su, T.-S., Hong, C.-Y., and Wei, T.-C. (2017). Crystal growth and dissolution of methylammonium lead iodide perovskite in sequential deposition: correlation between morphology evolution and photovoltaic performance. ACS Appl. Mater. Interfaces 9, 8623-8633. doi: 10.1021/acsami.6b12303

Jiang, Q., Zhao, Y., Zhang, X., Yang, X., Chen, Y., Chu, Z., et al. (2019). Surface passivation of perovskite film for efficient solar cells. Nat. Photon. 13, 460-466. doi: 10.1038/s41566-019-0398-2

Jung, E. H., Jeon, N. J., Park, E. Y., Moon, C. S., Shin, T. J., Yang, T.-Y., et al. (2019). Efficient, stable and scalable perovskite solar cells using poly(3hexylthiophene). Nature 567, 511-515. doi: 10.1038/s41586-019-1036-3

Kim, M., Kim, G. H., Lee, T. K., Choi, I. W., Choi, H. W., Jo, Y., et al. (2019). Methylammonium chloride induces intermediate phase stabilization for efficient perovskite solar cells. Joule 3, 2179-2192. doi: 10.1016/j.joule.2019.06.014

Lin, Q., Armin, A., Nagiri, R. C. R., Burn, P. L., and Meredith, P. (2015). Electro-optics of perovskite solar cells. Nat. Photon. 9, 106-112. doi: 10.1038/nphoton.2014.284

Liu, Y., Akin, S., Pan, L., Uchida, R., Arora, N., Milić, J. V., et al. (2019a). Ultrahydrophobic 3D/2D fluoroarene bilayer-based water-resistant perovskite solar cells with efficiencies exceeding 22\%. Sci. Adv. 5, 1-9. doi: 10.1126/sciadv.aaw2543

Liu, Z., Krückemeier, L., Krogmeier, B., Klingebiel, B., Márquez, J. A., Levcenko, S., et al. (2019b). Open-circuit voltages exceeding $1.26 \mathrm{~V}$ in planar methylammonium lead iodide perovskite solar cells. ACS Energy Lett. 4, 110-117. doi: 10.1021/acsenergylett.8b01906

Noel, N. K., Habisreutinger, S. N., Wenger, B., Klug, M. T., Hörantner, M. T., Johnston, M. B., et al. (2017). A low viscosity, low boiling point, clean solvent system for the rapid crystallisation of highly specular perovskite films. Energy Environ. Sci. 10, 145-152. doi: 10.1039/C6EE02373H

NREL (2020). Best Research-Cell Efficiencies. 
Petrov, A. A., Belich, N. A., Grishko, A. Y., Stepanov, N. M., Dorofeev, S. G., Maksimov, E. G., et al. (2017a). A new formation strategy of hybrid perovskites via room temperature reactive polyiodide melts. Mater. Horiz. 4, 625-632. doi: 10.1039/C7MH00201G

Petrov, A. A., Fateev, S. A., Zubavichus, Y. V., Dorovatovskii, P. V., Victor, N., Zvereva, I. A., et al. (2019). Methylammonium polyiodides: remarkable phase diversity of the simplest and low-melting alkylammonium polyiodide system. $J$. Phys. Chem. Lett. 10, 5776-5780. doi: 10.1021/acs.jpclett.9b02360

Petrov, A. A., Khrustalev, V. N., Zubavichus, Y. V., Dorovatovskii, P. V., Goodilin, E. A., and Tarasov, A. B. (2018). Synthesis and crystal structure of a new hybrid methylammonium iodocuprate. Mendeleev Commun. 28, 245-247. doi: 10.1016/j.mencom.2018.05.005

Petrov, A. A., Pellet, N., Seo, J.-Y., Belich, N. A., Kovalev, D. Y., Shevelkov, A. V., et al. (2017b). New insight into the formation of hybrid perovskite nanowires via structure directing adducts. Chem. Mater. 29, 587-594. doi: 10.1021/acs.chemmater.6b03965

Petrov, A. A., Sokolova, I. P., Belich, N. A., Peters, G. S., Dorovatovskii, P. V., Zubavichus, Y. V., et al. (2017c). Crystal structure of DMFintermediate phases uncovers the link between $\mathrm{CH} 3 \mathrm{NH} 3 \mathrm{PbI} 3$ morphology and precursor stoichiometry. J. Phys. Chem. C 121, 20739-20743. doi: $10.1021 /$ acs.jpcc.7b08468

Pistor, P., Ruiz, A., Cabot, A., and Izquierdo-Roca, V. (2016). Advanced Raman spectroscopy of methylammonium lead iodide: development of a non-destructive characterisation methodology. Sci. Rep. 6, 1-8. doi: $10.1038 /$ srep 35973

Saliba, M., Matsui, T., Seo, J.-Y. Y., Domanski, K., Correa-Baena, J.-P. P., Nazeeruddin, M. K., et al. (2016). Cesium-containing triple cation perovskite solar cells: improved stability, reproducibility and high efficiency. Energy Environ. Sci. 9, 1989-1997. doi: 10.1039/C5EE03874J

Shlenskaya, N. N., Belich, N. A., Grätzel, M., Goodilin, E. A., and Tarasov, A. B. (2018a). Light-induced reactivity of gold and hybrid perovskite as a new possible degradation mechanism in perovskite solar cells. J. Mater. Chem. A 6, 1780-1786. doi: 10.1039/C7TA10217H

Shlenskaya, N. N., Goodilin, E. A., and Tarasov, A. B. (2018b). Isolation of methylammonium room temperature reactive polyiodide melt into a new starch complex. Mendeleev Commun. 28, 242-244. doi: 10.1016/j.mencom.2018.05.004

Stegemann, H., Rohde, A., Reiche, A., Schnittke, A., and Füllbier, H. (1992). Room temperature molten polyiodides. Electrochim. Acta 37, 379-383. doi: 10.1016/0013-4686(92)87025-U

Thorsmølle, V. K., Brauer, J. C., Zakeeruddin, S. M., Grätzel, M., and Moser, J. E. (2012). Temperature-dependent ordering phenomena of a polyiodide system in a redox-active ionic liquid. J. Phys. Chem. C 116, 7989-7992. doi: $10.1021 /$ jp $300105 \mathrm{~h}$
Topol, L. E. (1968). Thermodynamic studies in the polyiodide systems, rubidium iodide-rubidium triiodide, ammonium iodide-ammonium triiodide, cesium iodide-cesium triiodide, and cesium triiodide-cesium tetraiodide. Inorg. Chem. 7, 451-454. doi: 10.1021/ic50061a013

Turkevych, I., Kazaoui, S., Belich, N. A., Grishko, A. Y., Fateev, S. A., Petrov, A. A., et al. (2019). Strategic advantages of reactive polyiodide melts for scalable perovskite photovoltaics. Nat. Nanotechnol. 14, 57-63. doi: 10.1038/s41565-018-0304-y

Udalova, N. N., Tutantsev, A. S., Chen, Q., Kraskov, A., Goodilin, E. A., and Tarasov, A. B. (2020). New features of photochemical decomposition of hybrid lead halide perovskites by laser irradiation. ACS Appl. Mater. Interfaces 12, 12755-12762. doi: 10.1021/acsami.9b21689

Wang, K. X., Yu, Z., Liu, V., Cui, Y., and Fan, S. (2012). Absorption enhancement in ultrathin crystalline silicon solar cells with antireflection and lighttrapping nanocone gratings. Nano Lett. 12, 1616-1619. doi: 10.1021/nl20 $4550 \mathrm{q}$

Wang, S., Jiang, Y., Juarez-Perez, E. J., Ono, L. K., and Qi, Y. (2016). Accelerated degradation of methylammonium lead iodide perovskites induced by exposure to iodine vapour. Nat. Energy 2:16195. doi: 10.1038/nenergy.20 16.195

Wang, Y., Xue, Y., Wang, X., Cui, Z., and Wang, L. (2014). The stable polyiodides: experimental and theoretical studies of formation mechanism. J. Mol. Struct. 1074, 231-239. doi: 10.1016/j.molstruc.2014.05.062

Yang, W. S., Park, B.-W., Jung, E. H., Jeon, N. J., Kim, Y. C., Lee, D. U., et al. (2017). Iodide management in formamidinium-lead-halide-based perovskite layers for efficient solar cells. Science 356, 1376-1379. doi: 10.1126/science.aa n2301

Yushina, I., Rudakov, B., Krivtsov, I., and Bartashevich, E. (2014). Thermal decomposition of tetraalkylammonium iodides. J. Therm. Anal. Calorim. 118, 425-429. doi: 10.1007/s10973-014-3944-7

Zhao, Y., and Zhu, K. (2016). Organic-inorganic hybrid lead halide perovskites for optoelectronic and electronic applications. Chem. Soc. Rev. 45, 655-689. doi: 10.1039/C4CS00458B

Conflict of Interest: The authors declare that the research was conducted in the absence of any commercial or financial relationships that could be construed as a potential conflict of interest.

Copyright $\odot 2020$ Petrov and Tarasov. This is an open-access article distributed under the terms of the Creative Commons Attribution License (CC BY). The use, distribution or reproduction in other forums is permitted, provided the original author(s) and the copyright owner(s) are credited and that the original publication in this journal is cited, in accordance with accepted academic practice. No use, distribution or reproduction is permitted which does not comply with these terms. 